\title{
Thermal Performance of an Energy Pile Group with a Deeply Penetrating U-Shaped Heat Exchanger
}

\author{
Weidong Lyu ${ }^{1} \mathbb{D}$, Hefu Pu ${ }^{1, *}$ and Jiannan (Nick) Chen ${ }^{2, *}$ \\ 1 Institute of Geotechnical and Underground Engineering, School of Civil and Hydraulic Engineering, \\ Huazhong University of Science and Technology, Wuhan 430074, China; weidonglyu@hust.edu.cn \\ 2 Department of Civil, Environmental, and Construction Engineering, University of Central Florida, \\ Orlando, FL 32816, USA \\ * Correspondence: puh@hust.edu.cn (H.P.); jiannan.chen@ucf.edu (J.C.); Tel.: +86-1777-186-8369 (H.P.)
}

Received: 7 October 2020; Accepted: 3 November 2020; Published: 6 November 2020

\begin{abstract}
This study presents a novel heat exchanger configuration, called a deeply penetrating U-shaped configuration, for energy piles. The outlet water temperature, temperature variation along the tube, and heat transfer rate are simulated and computed using Comsol Multiphysics software. The simulations are for the cooling mode. The proposed configuration is compared with traditional U-shaped and W-shaped configurations to prove its superiority. The thermal performance of the pile group is compared with that of a single pile to investigate the effects of the pile group on the heat transfer. A parametric analysis is performed to investigate the effects of several important parameters (i.e., pile spacing, pile diameter, soil type, and thermal parameters) on the heat transfer performance of an energy pile group with the proposed deeply penetrating U-shaped configuration. The results indicate that the corner pile indicates a nonnegligible heat transfer rate $6.8 \%$ and $9.9 \%$ higher than the central pile in quincuncial and squared arrangements. Purely from the standpoint of thermal performance, the pile spacing is recommended to be more than 6.8 times the pile diameter to reduce the influence of the pile group on the heat transfer capacity.
\end{abstract}

Keywords: geothermal energy; energy piles; deeply penetrating U-shaped configuration; heat exchanger; parametric analysis; pile group

\section{Introduction}

In recent years, the demand for renewable, clean, and efficient energy has been extended for sustainable development. As a green way of extracting heat from the ground in winter and releasing heat in summer, energy piles are gaining general attention worldwide. A ground source heat pump system combined with traditional pile foundations saves drilling costs and can meet both load-carrying capacity and the energy requirements. Geothermal energy is the main energy source, which leads to recyclable circuits in the energy piles. Compared with air conditioning systems, energy pile systems consume less energy [1], which shows attractive prospects and has attracted attention among researchers.

Studies have been conducted to analyze the costs, heat transfer rate, and coefficient of performance of ground source heat pump systems [1-9]. Tarnawski et al. found that a ground source heat pump system is a more beneficial alternative for space heating than an oil furnace or an electric resistance system [1]. Self et al. compared a ground source heat pump with conventional heating systems in terms of costs, $\mathrm{CO}_{2}$ emissions and other parameters and found that geothermal heat pumps are more efficient heating technologies [2]. Hamada et al. conducted a long-term space heating test with an energy pile system and indicated that the average coefficient of performance was quite high (=3.9) and that the seasonal primary energy reduction reached $23.2 \%$, compared with a typical air conditioning 
system [3]. Benli et al. developed a ground-source heat pump-phase change material latent heat storage system, and their results showed that the utilization of this system could be a suitable approach for greenhouse heating [4].

Energy piles can combine the advantages of a ground source heat pump and a pile foundation and thus have received extensive attention in recent years [10-19]. Adam introduced several applications that combined underground structures and ground heat pump systems [10]. Morino et al. conducted and simulated a heat exchange experiment employing a steel pile and then provided a calculation method that could predict the quantity of heat exchanged with the soil [12]. Abdelaziz et al. performed a series of numerical analyses to investigate the heat exchange behavior of energy piles for a variety of operational conditions [14]. Caulk et al. modeled four geothermal energy piles and calibrated them using field data, and an optimal cross-sectional heat exchanger geometry could be determined [16]. You et al. conducted a field energy pile test and simulated it to evaluate the heat exchange performance of an energy pile in a groundwater-rich area [17]. Batini et al. performed simulations to investigate the effects of different design parameters (including pipe configurations, aspect ratios of the foundation, fluid flow rates, and fluid mixture compositions) on the performance of the energy piles [18]. Jalaluddin conducted an experimental study of a steel energy pile foundation with U-tube, double-tube, and multiple-tube ground heat exchangers [19]. Overall, the studies above were focused on traditional configuration types (e.g., U-shaped, W-shaped and multi-U-shaped in series or parallel).

In addition to the traditional configuration types, other configuration types (e.g., spiral or helical, truncated cone helix, and elliptical single U-tube) were also proposed to increase the heat transfer capacity of energy piles [20-26]. For example, Bezyan et al. simulated a spiral-shaped configuration, then compared it with U-shaped and W-shaped configurations, and found that a spiral shape configuration with a $0.4 \mathrm{~m}$ pitch size indicated the highest heat transfer efficiency [20]. Zhao et al. simulated spiral-tube energy piles with four types of pitches and found that an increase in the spiral pitch results in a reduction of the mean coefficient of performance from $0.77 \%$ to $16.49 \%$ [21]. Carotenuto et al. compared the heat transfer efficiency of different configurations, including U-tubes, double U-tubes, triple U-tubes, and spiral coils [22]. The spiral shape configuration indicated a heat transfer rate that was only $6.9 \%$ lower than a double U-shaped configuration by employing only half the fluid flow rate. Huang et al. proposed a truncated cone helix energy pile and compared it with a cylinder helix energy pile and found that the novel energy pile indicated a higher heat transfer rate compared to the cylinder helix energy pile [24]. Jahanbin proposed a novel elliptical single U-tube that could enhance the heat transfer and decrease the thermal resistance by more than 17\% [26]. Overall, the literature indicated that novel configurations (mainly spiral or helical configuration) yielded better performance than U-shaped and W-shaped configurations.

Traditional energy piles have the following problems:

(1) The U-shaped configuration is simple in type. However, limited by the length of the pile, its heat transfer path is short, so the overall heat transfer efficiency is not high.

(2) Since the distance between the upward and downward heat exchange tubes of a W-shaped configuration is shorter than that of the U-type, thermal interference will occur and affect the tubes. Although the overall heat exchange efficiency will increase, the heat transfer rate per unit length of tube is not high. The multi-U-shaped configuration is similar.

(3) The multi-U-shaped configuration is complicated and difficult to construct, and there are problems with thermal interference and mutual influence among multiple U-shaped tubes.

(4) Spiral bends are more difficult, and greater thermal interference will also be formed inside the spiral. In addition, although the thermal interference can be reduced by increasing the spacing, the heat transfer efficiency per tube length is still not high. 
Based on the above shortcomings in traditional configurations, this study presents a novel heat exchanger configuration called a deeply penetrating U-shaped configuration. Compared with the above configurations, the proposed configuration can achieve the following beneficial effects:

(1) Compared with the U-shaped and W-shaped configurations, a deeply penetrating U-shaped configuration involves deeper soil, and as the temperature difference between deep soil and water is greater than that between shallow soil and water, the heat exchange is more effective at deeper soil levels for a deeply penetrating 1-U shaped configuration;

(2) Compared with the U-shaped configuration, the deep penetrating U-shaped configuration doubles the length of the heat transfer path and heat transfer time and thus results in a greater amount of heat exchange;

(3) Compared with the W-shaped configuration, the heat transfer length and time are nearly the same as those for the deeply penetrating U-shaped configuration, but the deeply penetrating U-shaped configuration has a greater lateral distance between the descending tube and ascending tube and thus has smaller thermal interference and higher heat transfer performance.

Few studies have focused on advancing the traditional U-shaped configuration [26]. Therefore, this study introduces a novel heat exchanger configuration, a deeply penetrating U-shaped configuration, for an energy pile. First, this study adopts a numerical finite element model of a pile group, which is verified against the experimental results in the literature. Second, the deeply penetrating U-shaped configuration is compared with traditional U-shaped and W-shaped configurations to prove its superiority. Third, a deeply penetrating U-shaped pile group is analyzed to research the effects of pile groups on heat transfer. Three typical pile positions in two arrangements are compared with a single pile. Last, a parametric analysis, including the pile spacing and pile diameter, is conducted to investigate the parameters affecting the thermal performance of the energy pile group with a deeply penetrating U-shaped heat exchanger.

\section{Materials and Methods}

\subsection{Characterization of an Energy Pile Group with a Deeply Penetrating U-Shaped Heat Exchanger}

An energy pile with a deeply penetrating $U$-shaped heat exchanger is a pile foundation in which the heat exchange tube is embedded and attached to a reinforcement cage, with the tube being arranged in a $U$ shape and its bottom penetrating through the bottom of the pile and sticking deeply into the soil below the pile. The absorber heat exchanger tubes are part of a closed circuit (primary circuit). This new type of energy pile has been patented in China [27], and its schematics are presented in Figure 1. The installation procedures are as follows (following Xiao et al. [28]): (1) cast the reinforced concrete pile, (2) drill a hole in the center of the pile and the soil below the pile all the way to the designated depth, (3) lower the heat exchange tube in the drilled hole, and (4) backfill the hole with concrete. Objectively speaking, the entire construction process is relatively more complicated than traditional energy piles. Theoretically, the soil underlying the pile base would have been disturbed due to the construction procedures, but the impact of heat exchanger installation on bearing capacity and heat transfer efficiency is limited because (a) the tube only takes up a very small portion of the cross-section of the pile, and (b) the impact of the drilling process on the pile body and the soil below is negligible because the drilled hole has a small diameter. Nonetheless, large-scale in situ experiments need to be conducted to further confirm the bearing capacity. 


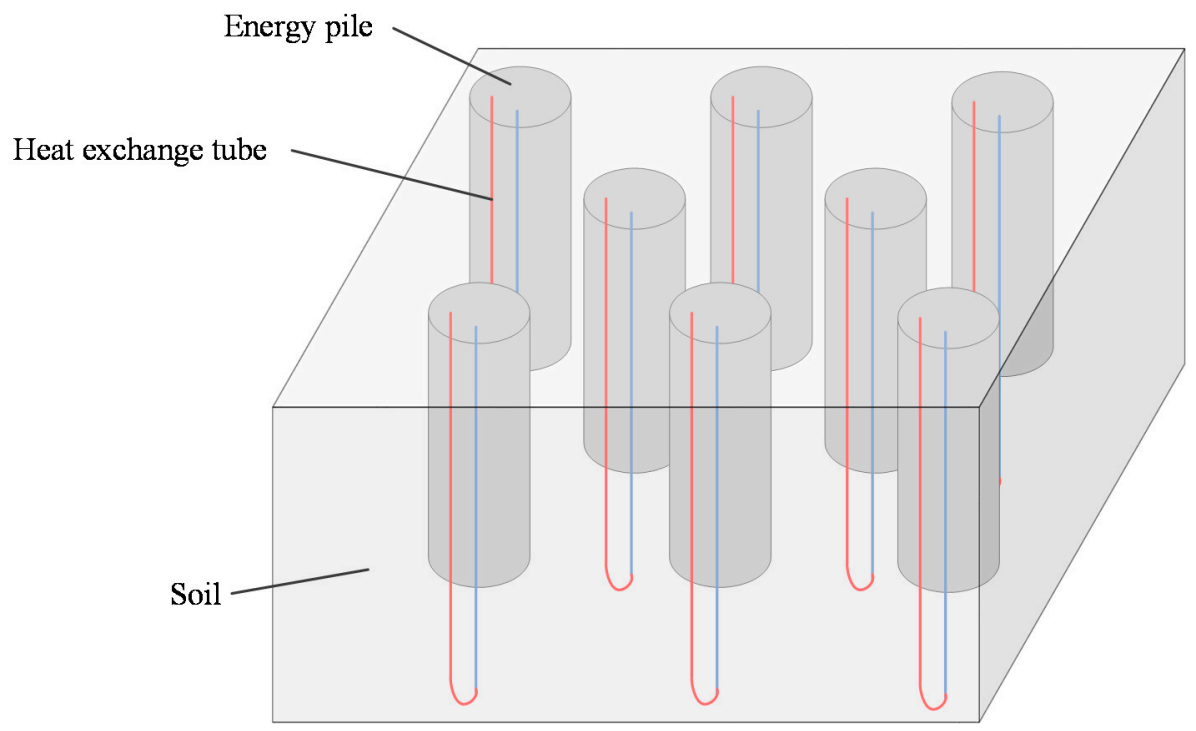

Figure 1. Schematics of the energy pile group embedded with a deeply penetrating U-shaped heat exchanger.

\subsection{Numerical Model}

This study adopts the finite element method. A transient model based on a one-dimensional approach for the heat and mass transfer in the tube and a three-dimensional approach for the heat transfer in the pile and soil was utilized. Comsol Multiphysics is used to simulate the model. A soil domain with a depth of $52 \mathrm{~m}$, a width of $30 \mathrm{~m}$, and a length of $30 \mathrm{~m}$ was established in the following simulations. This domain was large enough to ensure a sufficient heat transfer medium throughout and a constant soil temperature at the bottom, as suggested by Carotenuto et al. [22]. The soil types were mainly sandy silt, silty clay, and gravel. More detailed information on the soil is provided by You et al. [29]. The physical properties of the material are presented in Table 1 unless stated otherwise (data from Carotenuto et al. [22] and Bezyan et al. [20]). Figure 2 shows the tube positions at the pile head section adopted in this paper. The simulations are for the cooling mode.

Table 1. The physical properties of the material [20,22]. Reprint with permission [4942830196112] from Applied Thermal Engineering; published by Elsevier (Amsterdam, The Netherlands), Aug. 2015, and permission [4942931443346] from Applied Thermal Engineering; published by Elsevier, Sep. 2017.

\begin{tabular}{|c|c|c|c|}
\hline Material & $\begin{array}{l}\text { Thermal Conductivity, } k_{s} \\
(\mathrm{~W} / \mathrm{m} \cdot \mathrm{K})\end{array}$ & $\begin{array}{c}\text { Specific Heat Capacity, } c_{s} \\
(\mathrm{~J} / \mathrm{kg} \cdot \mathrm{K})\end{array}$ & Density, $\rho_{s}\left(\mathrm{~kg} / \mathrm{m}^{3}\right)$ \\
\hline Soil & 1.3 & 1200 & 1847 \\
\hline Concrete & 1.628 & 837 & 2500 \\
\hline Tube & 0.42 & 1465 & 1100 \\
\hline Water & 0.6 & 4182 & 998.2 \\
\hline
\end{tabular}

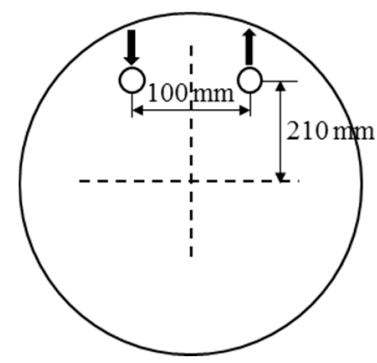

Figure 2. Tube positions at the pile head section. 


\subsubsection{Solution Algorithms and Simulation Method}

The heat transfer behavior of the energy piles includes conduction in the concrete and soil and convection between the water and tube. Water convection in the soil is neglected in this study. The three-dimensional transient heat transfer in the concrete and soil is conduction and is described as follows [30]:

$$
\rho_{s} \mathcal{c}_{s} \frac{\partial T}{\partial t}-\operatorname{div}\left(k_{s} \operatorname{grad} T\right)=0
$$

where $\rho_{s}$ is the density of the soil or concrete $\left(\mathrm{kg} / \mathrm{m}^{3}\right), c_{s}$ is the specific heat capacity $(\mathrm{J} / \mathrm{kg} \cdot \mathrm{K}), T$ is the temperature $(\mathrm{K}), t$ is the time $(\mathrm{s})$, div is the divergence operator, $k_{s}$ is the thermal conductivity $(\mathrm{W} / \mathrm{m} \cdot \mathrm{K})$, and grad is the gradient operator.

Because the radial directional size of the tube is very small compared with its axial directional size, a one-dimensional dynamic heat and mass transfer model, the "nonisothermal pipe flow" module in Comsol Multiphysics, is adopted for the simulation. The equations are as follows [31]:

Continuity equation:

$$
\frac{\partial A \rho_{w}}{\partial t}+\frac{\partial A \rho_{w} u}{\partial x}=0
$$

Momentum conservation equation:

$$
\rho_{w} \frac{\partial u}{\partial t}=-\frac{\partial p}{\partial x}-\frac{1}{2} f_{d} \frac{\rho_{w}}{D_{h}}|u| u
$$

Energy conservation equation:

$$
\rho_{w} A c_{w} \frac{\partial T}{\partial t}+\rho_{w} A c_{w} u \frac{\partial T}{\partial x}=\frac{\partial}{\partial x}\left(A k_{w} \frac{\partial T}{\partial x}\right)+\frac{1}{2} f_{d} \frac{\rho_{w} A}{D_{h}}|u| u^{2}+Q_{w a l l}
$$

where $A$ is the cross-sectional area of the tube $\left(\mathrm{m}^{2}\right), \rho_{w}$ is the density of water $\left(\mathrm{kg} / \mathrm{m}^{3}\right), u$ is the flow velocity of water $(\mathrm{m} / \mathrm{s}), p$ is the water pressure $(\mathrm{Pa}), D$ is the hydraulic diameter of the tube, $f_{d}$ is the friction factor dependent on the Reynolds number as well as the ratio of the tube thickness to the hydraulic diameter of the tube, $c_{w}$ is the specific heat capacity of water $(\mathrm{J} / \mathrm{kg} \cdot \mathrm{K}), k_{w}$ is the thermal conductivity of water $(\mathrm{W} / \mathrm{m} \cdot \mathrm{K})$, and $Q_{\text {wall }}$ is the exchanged heat transfer rate per unit length through the tube wall $(\mathrm{W} / \mathrm{m})$, which is calculated as follows [22]:

$$
\begin{gathered}
Q_{\text {wall }}=K_{T}\left(T_{\text {ext }}-T\right) \\
K_{T}=\frac{2 \pi}{\frac{1}{r_{i} h_{i}}+\frac{\ln \left(\frac{r_{e}}{r_{i}}\right)}{k_{t}}}
\end{gathered}
$$

where $K_{T}$ is the thermal transmittance of the tube $(\mathrm{W} / \mathrm{m} \cdot \mathrm{K}), T_{\text {ext }}$ is the concrete temperature $(\mathrm{K}), r_{i}$ and $r_{e}$ are the internal and external radii of the tube (m), respectively, $h_{i}$ is the convective heat transfer coefficient inside the tube $\left(\mathrm{W} / \mathrm{m}^{2} \cdot \mathrm{K}\right)$, and $k_{t}$ is the thermal conductivity of the tube $(\mathrm{W} / \mathrm{m} \cdot \mathrm{K})$.

The main purpose of the energy piles is to reduce the water temperature in summer. Thus, the heat transfer rate $Q(\mathrm{~W})$ and heat transfer rate per unit length of tube $Q^{*}(\mathrm{~W} / \mathrm{m})$, which can be calculated as follows [32]:

$$
\begin{gathered}
Q=c_{w} \Delta m \Delta T=c_{w} \rho_{w} v\left(T_{\text {in }}-T_{\text {out }}\right) \\
Q^{*}=\frac{Q}{L}=\frac{c_{w} \rho_{w} v\left(T_{\text {in }}-T_{\text {out }}\right)}{L}
\end{gathered}
$$

where $\Delta m$ is the water mass per unit time $(\mathrm{kg} / \mathrm{s}), \Delta T$ is the inlet and outlet water temperature variation $\left({ }^{\circ} \mathrm{C}\right), T_{\text {in }}$ is the inlet water temperature $(\mathrm{K}), T_{\text {out }}$ is the outlet water temperature $(\mathrm{K}), v$ is the volumetric flow rate of water $\left(\mathrm{m}^{3} / \mathrm{s}\right)$, and $L$ is the tube length $(\mathrm{m})$. 


\subsubsection{Boundary and Initial Conditions}

The boundary and initial conditions for the numerical simulations are presented in Figure 3. Physically, the top ground surface is not adiabatic, but it is subject to convective boundary conditions with air. However, through preliminary simulation analysis, we find that the difference between the results of using the adiabatic boundary and the convection boundary can be ignored, and the calculation efficiency from using the adiabatic boundary is much faster, so the adiabatic boundary is used on the top surface. The reason for this is mainly because temperature boundary conditions are imposed on the surroundings, which are the most relevant to the results. Therefore, in this study, the top surface of the ground is specified as adiabatic, which reproduces what happens in the ground. The bottom is specified to have a constant temperature, which is the yearly average temperature of the ground. The lateral surface of the ground is specified considering the variation in depth and time [33], which is assumed to be the following equation:

$$
T(z, t)=T_{\text {ave }}+A_{0} \exp \left(-\frac{z}{d}\right) \sin \left(\omega t-\frac{z}{d}\right)
$$

where $T_{\text {ave }}$ is the annual average temperature $(\mathrm{K})$; this temperature is the temperature at which the internal heat of the earth and the sun's radiant heat reach equilibrium, and it mainly changes with the latitude of the earth. For the European constant temperature zone, the average temperature is $10-15^{\circ} \mathrm{C}$, while the tropical constant temperature zone located near the equator has an average temperature of $20-25^{\circ} \mathrm{C} . A_{0}$ is the maximum annual amplitude of the temperature $(\mathrm{K})$, which refers to the degree at which the temperature field of the outermost layer of the earth is affected by solar radiation heat. $z$ is the depth $(\mathrm{m})$, and $d$ is the damping depth of the annual fluctuation of the temperature $(\mathrm{m})$, which refers to the range in which the temperature field of the surface layer of the earth is affected by solar radiation heat; $t$ is the time (day), and $\omega$ is the annual radial frequency (1/day), which is mainly affected by seasonal changes; $t$ and $\omega$ together refer to the season. Equation (9) defines that temperature changes with depth and season.

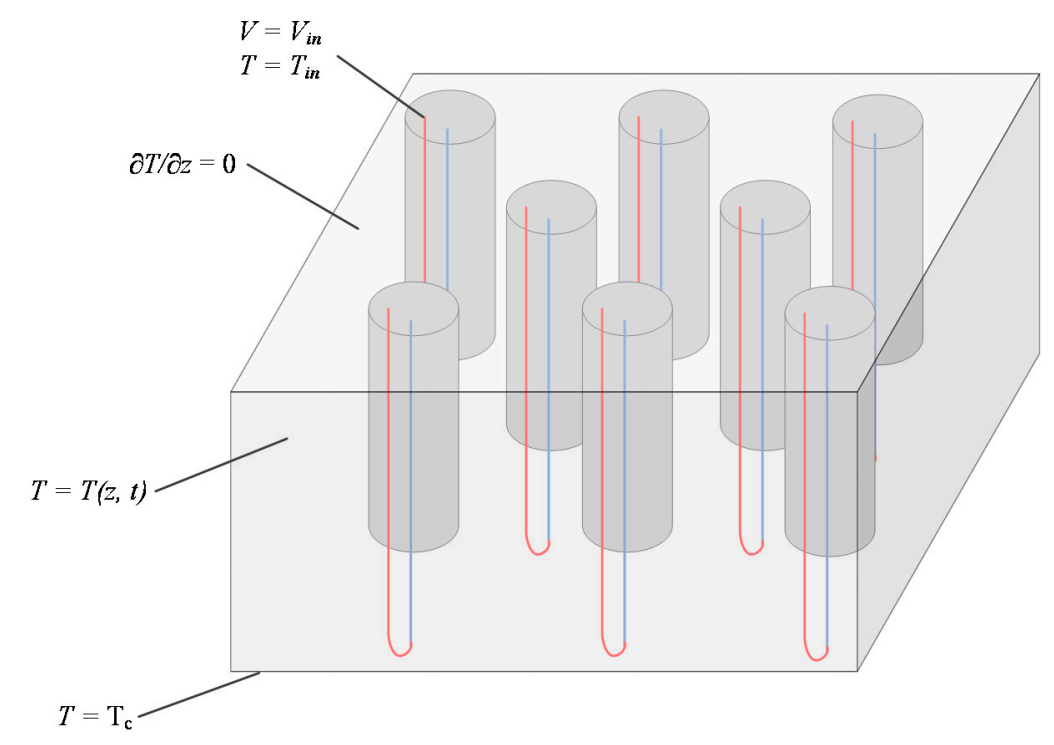

Figure 3. Boundary and initial conditions employed in the numerical simulations.

The initial conditions of the temperature are also specified according to Equation (9) considering the temperature variation with depth. A constant velocity and temperature of water are imposed on the inlet section, and no temperature variation or prescribed pressure is specified on the outlet section. 


\subsubsection{Modeling and Meshing Configuration}

For the following validation, comparison and parametric analysis, there are tables that introduce detailed information for the modeling and meshing configurations, so it is not reported here for the sake of brevity. In general, mesh elements are composed of tetrahedral elements and are strengthened near the tube. The sensitivity analysis of the grid is carried out in the early stage. Then, finer meshing is adopted to ensure accuracy while ensuring efficiency.

\subsection{Model Validation}

\subsubsection{Validation for a Single Pile}

First, the proposed numerical model is used to simulate a single pile with a U-shaped heat exchanger, which is based on Gao et al.'s experiment [32]. In situ cast concrete bearing energy piles were installed in Shanghai, China. The depth of frozen earth in Shanghai is approximately $8 \mathrm{~cm}$, and the soil temperature at a depth of $5 \mathrm{~m}$ remains almost constant. The parameters of the energy pile are presented in Table 2 (data from Gao et al. [32]). In accordance with the in situ experiments, the simulation is performed with a time period of $3 \mathrm{~h}$ [32]. The comparison of the outlet water temperature between the simulation and experimental data is presented in Table 3, and excellent agreement is observed.

Table 2. Energy pile parameters for Gao et al.'s experiment. [32]. Reprint with permission [4942930442751] from Applied Thermal Engineering; published by Elsevier, Dec. 2008.

\begin{tabular}{cc}
\hline Parameter & Value \\
\hline Soil Domain $(\mathrm{m})$ & $5 \times 5 \times 35$ \\
Pile Length $(\mathrm{m})$ & 25.5 \\
Pile Diameter $(\mathrm{m})$ & 0.6 \\
Tube Configuration & U-shaped \\
Tube Diameter $(\mathrm{mm})$ & 20 \\
Tube Thickness $(\mathrm{mm})$ & 4 \\
Tube Depth $(\mathrm{m})$ & 25 \\
Water Flow Rate $\left(\mathrm{m}^{3} / \mathrm{h}\right)$ & 0.342 \\
Inlet Water Temperature $\left({ }^{\circ} \mathrm{C}\right)$ & 35 \\
Annual Average Temperature $\left({ }^{\circ} \mathrm{C}\right)$ & 18.2 \\
Operating Mode & summer \\
Testing Time $(\mathrm{h})$ & 3 \\
\hline
\end{tabular}

Table 3. Comparison of the outlet water temperature after $3 \mathrm{~h}$ of cooling between the present study and Gao et al.'s experiment [32]. Reprint with permission [4942930442751] from Applied Thermal Engineering; published by Elsevier, Dec. 2008.

\begin{tabular}{ccccc}
\hline & $\begin{array}{c}\text { Inlet Water } \\
\text { Temperature, } \boldsymbol{T}_{\text {in }}\left({ }^{\circ} \mathbf{C}\right)\end{array}$ & $\begin{array}{c}\text { Outlet Water } \\
\text { Temperature, } \boldsymbol{T}_{\text {out }}\left({ }^{\circ} \mathbf{C}\right)\end{array}$ & $\begin{array}{c}\text { Temperature } \\
\text { Variation, } \boldsymbol{\Delta} \boldsymbol{T}\left({ }^{\circ} \mathbf{C}\right)\end{array}$ & $\begin{array}{c}\text { Heat Transfer } \\
\text { Rate, } \boldsymbol{Q}(\mathbf{W})\end{array}$ \\
\hline This study & 35 & 31.64 & 3.37 & 2365 \\
Gao et al. [32] & 35.13 & 31.56 & 3.57 & 2505 \\
\hline
\end{tabular}

\subsubsection{Validation for a Pile Group}

To validate the numerical model for a pile group, a group of three parallel piles was simulated against You et al.'s [29] in situ experiments. In situ experiments of cement-fly ash-gravel energy piles were conducted at a testing field in Shunyi, Beijing. The piles had a diameter of $0.42 \mathrm{~m}$, a length of $18 \mathrm{~m}$, and a spacing of $2 \mathrm{~m}$. Three piles connected in parallel were tested after the pile temperature had returned to the original soil temperature. More details on the parameters of the energy pile group are presented in Table 4 (data from You et al. [29]). The material properties are consistent with those presented in Table 1, according to Carotenuto et al. and You et al.'s work [29]. The geometry 
model is presented in Figure 4a, and the mesh distribution is presented in Figure $4 \mathrm{~b}$. The boundary conditions are the same as in Figure 3. Overall, there is good agreement between the present study and You et al.'s work. Taking the central pile as an example, according to Table 5, the outlet water temperature is $32.85^{\circ} \mathrm{C}$ in this study, and the temperature variation between the inlet and outlet is $2.15^{\circ} \mathrm{C}$, while the temperature difference is $1.96^{\circ} \mathrm{C}$ in You et al.'s work. The slight difference between the present study and the experimental data can be due to the uncertainty in the values employed for the thermal properties of the soil, which is composed of several layers.

Table 4. Parameters of the energy pile of You et al.'s experiments [29]. Reprint with permission [4942921402906] from Energy and Buildings; published by Elsevier, Aug. 2014.

\begin{tabular}{cc}
\hline Parameter & Value \\
\hline Pile Length $(\mathrm{m})$ & 18 \\
Pile Diameter $(\mathrm{m})$ & 0.42 \\
Pile Spacing $(\mathrm{m})$ & 2 \\
Tube Configuration & -shaped \\
Tube Depth $(\mathrm{m})$ & 17.5 \\
Tube Diameter $(\mathrm{mm})$ & 25 \\
Tube Thickness $(\mathrm{mm})$ & 4 \\
Water Flow Velocity $(\mathrm{m} / \mathrm{s})$ & 0.51 \\
Ambient Temperature $\left({ }^{\circ} \mathrm{C}\right)$ & 16 \\
Operating Mode & summer \\
Inlet Water Temperature $\left({ }^{\circ} \mathrm{C}\right)$ & 35 \\
\hline
\end{tabular}

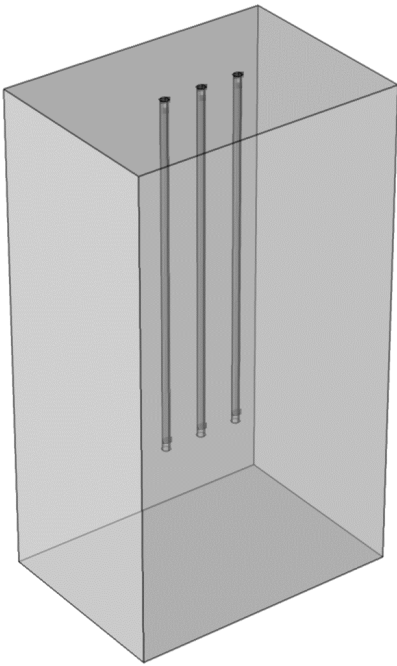

(a)

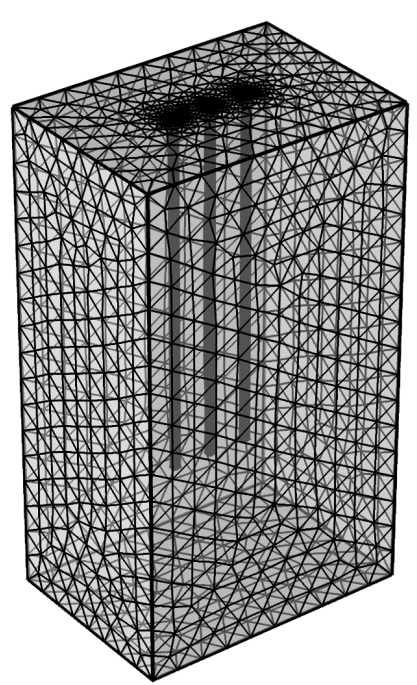

(b)

Figure 4. (a) The geometry model; (b) the mesh distribution.

Table 5. Comparison of the outlet water temperature after $50 \mathrm{~h}$ of cooling between the present study and You et al.'s experiments [29]. Reprint with permission [4942921402906] from Energy and Buildings; published by Elsevier, Aug. 2014.

\begin{tabular}{ccccc}
\hline & $\begin{array}{c}\text { Inlet water } \\
\text { Temperature, } \boldsymbol{T}_{\text {in }}\left({ }^{\circ} \mathrm{C}\right)\end{array}$ & $\begin{array}{c}\text { Outlet Water } \\
\text { Temperature, } \boldsymbol{T}_{\text {out }}\left({ }^{\circ} \mathrm{C}\right)\end{array}$ & $\begin{array}{c}\text { Temperature } \\
\text { Variation, } \Delta \boldsymbol{T}\left({ }^{\circ} \mathrm{C}\right)\end{array}$ & $\begin{array}{c}\text { Heat Transfer } \\
\text { Rate, } \boldsymbol{Q}(\mathrm{W})\end{array}$ \\
\hline This study & \multirow{2}{*}{35} & 32.85 & 2.15 & 2260 \\
You et al. [29] & & 33.04 & 1.96 & 2070 \\
\hline
\end{tabular}




\section{Results and Discussion}

\subsection{Comparison of U-Shaped, W-Shaped, and Deeply Penetrating U-Shaped Configurations}

To demonstrate the superior heat transfer efficiency of the proposed deeply penetrating U-shaped configuration, three heat exchanger configurations (i.e., U-shaped configuration, W-shaped configuration, and deeply penetrating U-shaped configuration) are compared. The parameters of the energy pile with these three different configurations are presented in Table 2 (data from Gao et al. [32]). In addition, the depth of the penetrating tubes for the deep penetrating U-shaped configuration is $51 \mathrm{~m}$, which is the double pile length. The test time is $50 \mathrm{~h}$. The obtained results are shown in Figure 5 and Table 6. Figure 5 shows the water temperature variation along the tube for the three different configurations, and Table 6 presents the outlet water temperature and heat transfer rate for the three configurations. Table 6 indicates that the total heat transfer rate $Q$ for the deeply penetrating U-shaped configuration is $122 \%$ and $54 \%$ higher than that for the U-shaped and W-shaped configurations, respectively. In terms of the heat transfer rate per unit length of tube $Q^{*}$, the value for the deeply penetrating U-shaped configuration is $9 \%$ and $50 \%$ higher than that for the U-shaped and W-shaped configurations, respectively. These data indicate that the deeply penetrating U-shaped configuration provides superior thermal performance to the traditional U-shaped and W-shaped configurations. The major reasons for its superior performance are as follows. First, compared with the U-shaped and W-shaped configurations, the deeply penetrating U-shaped configuration involves deeper soil, and as the temperature difference between the deep soil and water is greater than that between the shallow soil and water, the heat exchange is more effective in deeper soil for the deeply penetrating U-shaped configuration. Second, compared with the U-shaped configuration, the deep penetrating U-shaped configuration doubles the length of the heat transfer path and heat transfer time and thus has a greater amount of heat exchange. Third, compared with the W-shaped configuration, the heat transfer length and time are nearly the same as those for the deeply penetrating U-shaped configuration, but the deeply penetrating U-shaped configuration has a greater lateral distance between the descending tube and ascending tube and thus has smaller thermal interference and higher heat transfer performance.

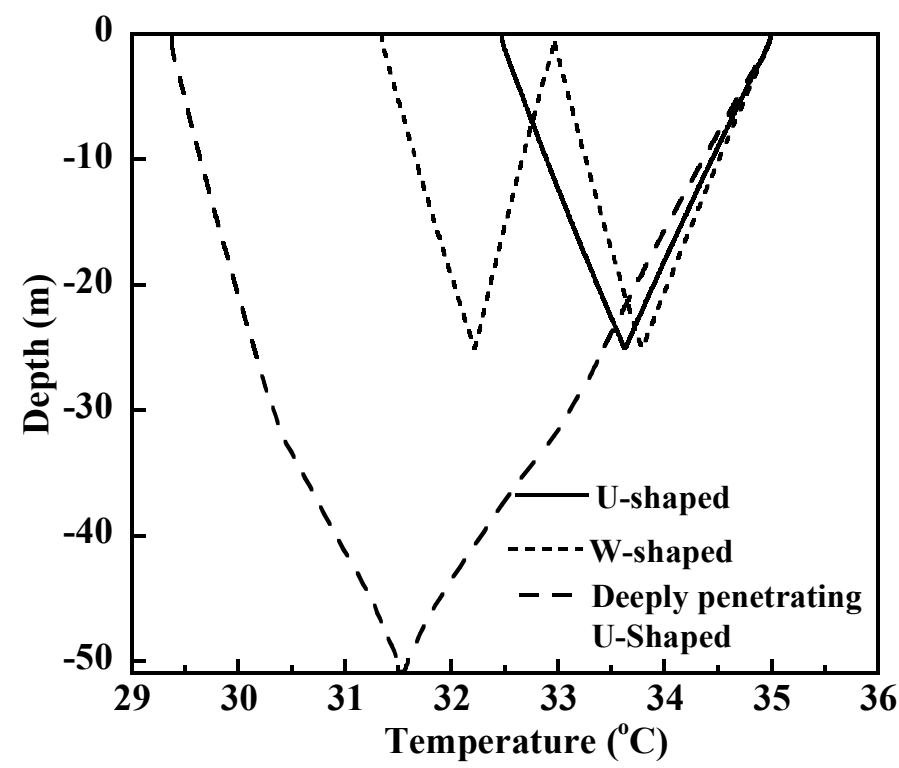

Figure 5. Temperature variation along the tube after $50 \mathrm{~h}$ of cooling: comparison between deeply penetrating U-shaped configuration versus U-shaped and W-shaped configurations. 
Table 6. Comparison of thermal performance for three different tube configurations.

\begin{tabular}{cccc}
\hline Tube Configuration & $\begin{array}{c}\text { Outlet Water } \\
\text { Temperature, } \boldsymbol{T}_{\text {out }}\left({ }^{\circ} \mathbf{C}\right)\end{array}$ & Heat Transfer Rate, $Q(\mathrm{~W})$ & $\begin{array}{c}\text { Heat Transfer Rate per Unit } \\
\text { Length of Tube, } Q^{*}(\mathbf{W} / \mathbf{m})\end{array}$ \\
\hline U-Shaped & 32.47 & 995 & 19.85 \\
W-Shaped & 31.35 & 1436 & 14.44 \\
Deeply Penetrating & 29.38 & 2211 & 21.64 \\
U-Shaped & & 2 & \\
\hline
\end{tabular}

3.2. Comparison of Energy Pile in Pile Group with Quincuncial Arrangement, Squared Arrangement and Single Pile

For an energy pile group with a deep penetration U-shaped heat exchanger, it is important to analyze the effect of pile arrangement on thermal performance. Two common arrangements (i.e., quincuncial and squared arrangements) are discussed in this paper.

To investigate the effects of different types of pile groups on the heat transfer performance, a pile group with 8 or 9 piles is taken as a unit for analysis. The pile numbers are designated as shown in Figure 6. Meanwhile, the configurations of the single pile and the pile group are consistent for the sake of easy comparison, which are presented in Table 2 (data from Gao et al. [32]). In addition, the depth of the penetrating tubes for the deep penetrating U-shaped configuration is $51 \mathrm{~m}$, which is the double pile length. The pile spacing (i.e., distance between adjacent pile centers) is $2.6 \mathrm{~m}$ for the pile group, and the test time is $720 \mathrm{~h}$. The geometry model is presented in Figures $7 \mathrm{a}$ and $8 \mathrm{a}$, and the mesh distribution is presented in Figures $7 \mathrm{~b}$ and $8 \mathrm{~b}$. The simulation results are presented in Figures 9 and 10 and Table 7. Figure 9 presents the outlet water temperature variation with time for different piles in the pile group in a quincuncial arrangement and compares it with that of a single pile. Figure 10 presents the corresponding comparison between the pile group in the squared arrangement and the single pile. Table 7 presents the outlet water temperature, temperature variation and heat transfer rate of Pile \#1, Pile \#2, and Pile \#3 in the quincuncial arrangement versus Pile \#4, Pile \#5, and Pile \#6 in the squared arrangement and a single pile after $720 \mathrm{~h}$ of operation.

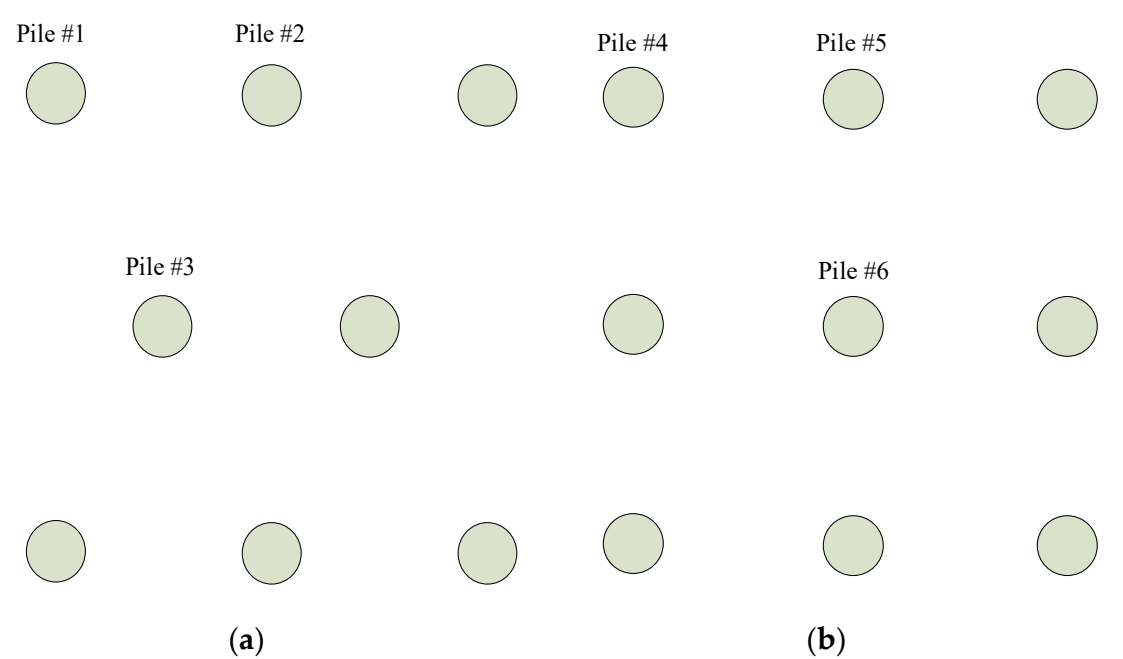

Figure 6. The pile number designation in (a) quincuncial arrangement, (b) squared arrangement. 


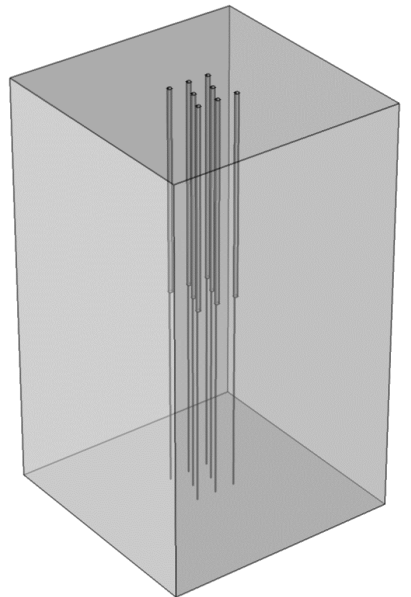

(a)

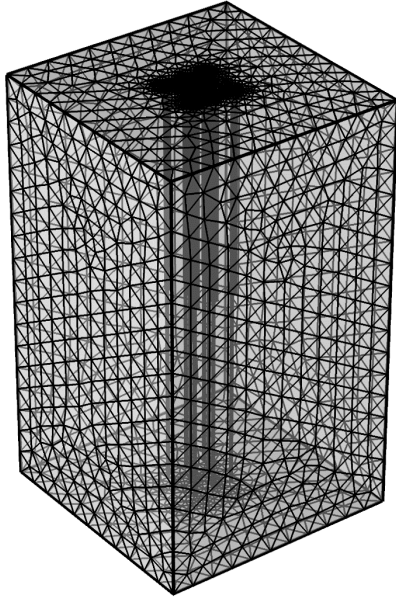

(b)

Figure 7. (a) The geometry model, (b) The mesh distribution of quincuncial arrangement.

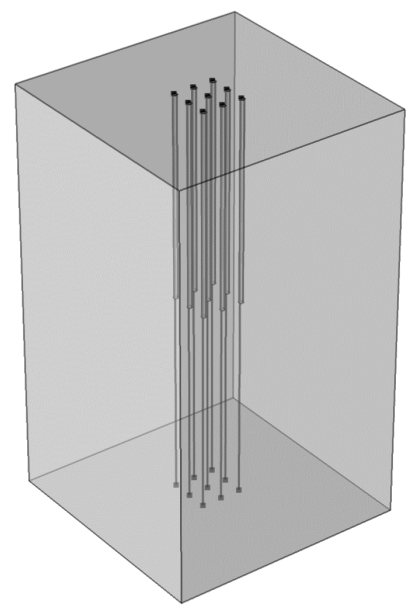

(a)

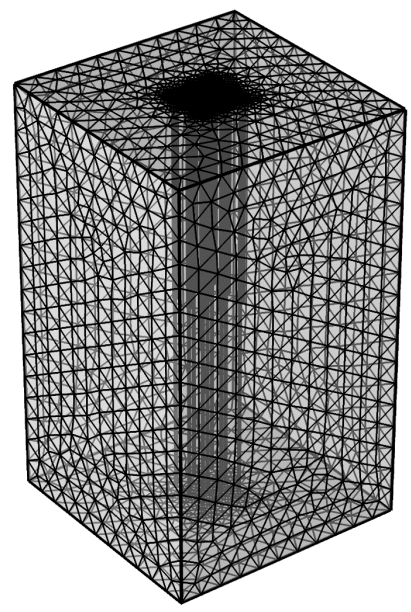

(b)

Figure 8. (a) The geometry model, (b) The mesh distribution of squared arrangement.

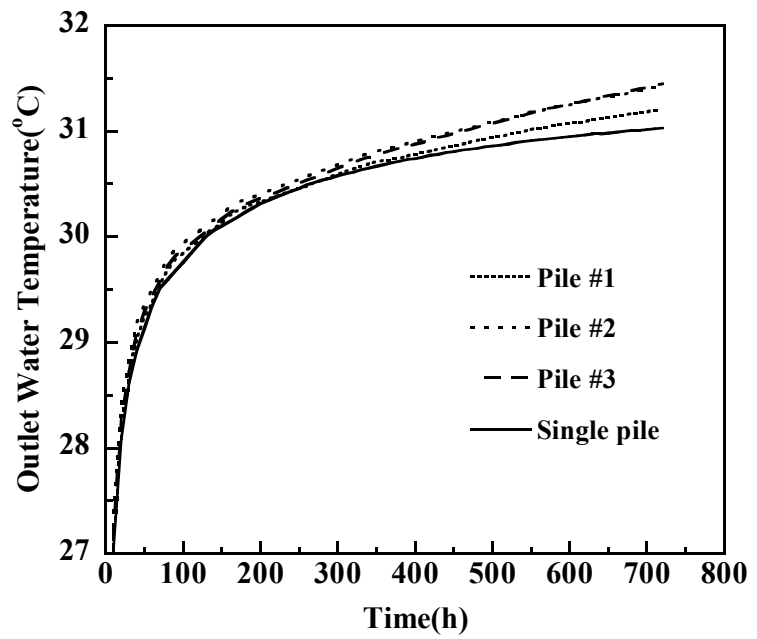

Figure 9. Outlet water temperature variation of Piles \#1,\#2, and \#3 in the quincuncial arrangement and the single pile. 


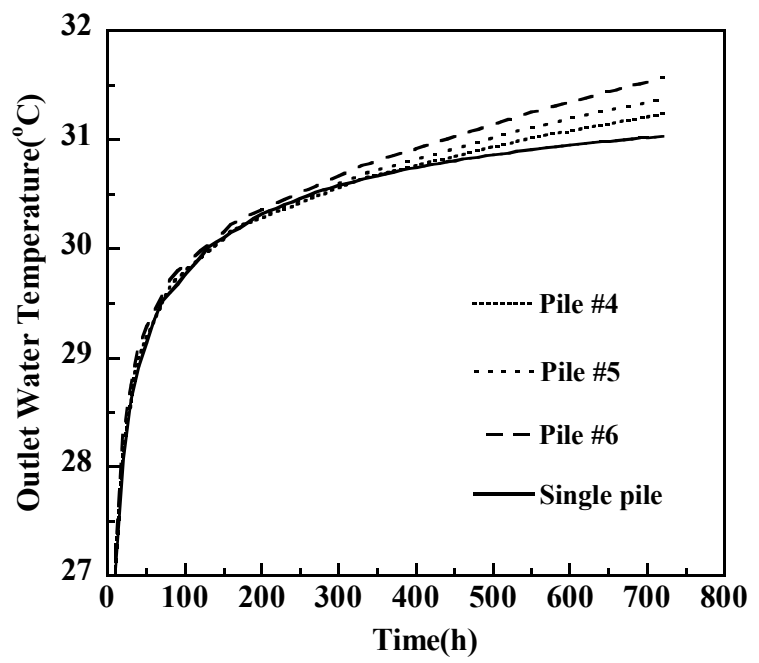

Figure 10. Outlet water temperature variation of Piles \#4, \#5, and \#6 in the squared arrangement and the single pile.

Table 7. Comparison of thermal performance between Piles\#1, \#2, and \#3 in the quincuncial arrangement versus Piles \#4, \#5, and \#6 in the squared arrangement and single pile.

\begin{tabular}{|c|c|c|c|c|c|}
\hline $\begin{array}{c}\text { Pile } \\
\text { Arrangement }\end{array}$ & Pile Number & $\begin{array}{c}\text { Inlet Water } \\
\text { Temperature, } T_{i n}\left({ }^{\circ} \mathrm{C}\right)\end{array}$ & $\begin{array}{c}\text { Outlet Water } \\
\text { Temperature, } T_{\text {out }}\left({ }^{\circ} \mathrm{C}\right)\end{array}$ & $\begin{array}{c}\text { Temperature } \\
\text { Variation, } \Delta T\left({ }^{\circ} \mathrm{C}\right)\end{array}$ & $\begin{array}{l}\text { Heat Transfer } \\
\text { Rate, } Q(\mathrm{~W})\end{array}$ \\
\hline \multirow{2}{*}{ Quincuncial } & 1 & & 31.21 & 3.79 & 2659 \\
\hline & 3 & & 31.45 & 3.55 & 2491 \\
\hline \multirow[b]{2}{*}{ Squared } & 4 & 35 & 31.23 & 3.77 & 2646 \\
\hline & 5 & & 31.37 & 3.63 & 2547 \\
\hline
\end{tabular}

According to Figure 9, in the first $300 \mathrm{~h}$, the outlet water temperatures of Piles \#1, \#2, and \#3 were nearly the same and had negligible differences from the single pile. This indicates that $300 \mathrm{~h}$ is not long enough to cause thermal interference. After $300 \mathrm{~h}$, however, the difference became more evident. After $720 \mathrm{~h}$, the outlet water temperatures of Piles $\# 2$ and $\# 3$ were nearly the same $\left(31.43^{\circ} \mathrm{C}\right.$ and $\left.31.45^{\circ} \mathrm{C}\right)$, while that of Pile $\# 1$ was slightly lower $\left(31.21^{\circ} \mathrm{C}\right)$. The heat transfer rate of Pile \#1 is $6.2 \%$ and $6.8 \%$ higher than that of Piles \#2 and \#3, respectively, because the thermal interference at the corner (Pile \#1) was not significant compared with that at the side (Pile \#2) or that at the center (Pile \#3).

According to Figure 10, in the first $300 \mathrm{~h}$, Piles \#4, \#5 and \#6 have negligible differences from the single pile. This also indicates that $300 \mathrm{~h}$ is not long enough to cause thermal interference. After $300 \mathrm{~h}$, thermal interference becomes evident, which causes a decrease in the heat transfer capacity. After $720 \mathrm{~h}$, Pile \#6 (at the center) had the highest outlet water temperature of $31.57^{\circ} \mathrm{C}$. Pile \#5 (at the side) had the second highest outlet water temperature $\left(31.37^{\circ} \mathrm{C}\right)$, and Pile \#4 (at the corner) had the lowest outlet water temperature $\left(31.23^{\circ} \mathrm{C}\right)$. Meanwhile, the outlet water temperature of the single pile is $31.03^{\circ} \mathrm{C}$, which is lower than that of all the piles in the group. The corner pile indicates a heat transfer rate 9.9\% higher than the central pile. The reasons are as follows: the thermal interference increases with increasing operating time. Pile \#6 is at the center and thus subject to the greatest thermal interference from surrounding piles. Pile \#4 is at the corner and thus subject to the least thermal interference.

After $720 \mathrm{~h}$, the outlet water temperatures of different piles in different arrangement forms are listed in Table 7. As shown in Table 7, the outlet water temperature of Pile \#4 was higher than Pile \#1, and Pile \#6 was higher than Pile \#3, but Pile \#5 was lower than Pile \#2. The difference between Piles \#3 and \#6 was the greatest $\left(0.12{ }^{\circ} \mathrm{C}\right)$. This indicates that the thermal interference of the corner pile and central pile in the squared pile arrangement was greater than that in the quincuncial arrangement. 
The thermal interference of the pile at the side in the squared arrangement was not as great as that in the quincuncial arrangement. In addition, the center is the area was where the difference in outlet water temperature was the most obvious when comparing different arrangement forms. The central pile in the quincuncial arrangement indicated a heat transfer rate $3.5 \%$ higher than the central pile in the squared arrangement.

In practical projects, pile groups are usually more than nine piles, especially for large buildings. The quincuncial or squared arrangement that we simulated is only a small unit. Most piles are at the center, such as Piles \#3 and \#6. In other words, a quincuncial arrangement is recommended to increase the heat exchange capacity when there are a large number of piles. When only a limited number of piles were used, these two arrangement forms exhibited no large differences.

\subsection{Parametric Analysis}

After verification and comparison, the energy pile group with a deeply penetrating U-shaped heat exchanger was adopted to analyze the factors affecting the pile group heat exchange performance. Several key parameters (i.e., pile spacing and pile diameter) were investigated. Table 8 presents the variation range of the above parameter values for the parametric analysis.

Table 8. Variation range of the parameter values for the parametric analysis.

\begin{tabular}{cc}
\hline Pile Spacing, $S(\mathbf{m})$ & Pile Diameter, $D_{p}(\mathbf{m m})$ \\
\hline 2.1 & 400 \\
2.6 & 600 \\
3.1 & 800 \\
3.6 & 1000 \\
4.1 & - \\
4.6 & - \\
\hline
\end{tabular}

The operating time is $720 \mathrm{~h}$ in the cooling mode (summer), and the baseline conditions of the simulations for the parametric analysis are consistent with Table 2. The baseline condition is pile spacing $=2.6 \mathrm{~m}$ and pile diameter $=0.6 \mathrm{~m}$.

For each series of simulations, only the variable of interest was changed, with the other variables kept constant and equal to those for the corresponding baseline conditions, unless otherwise stated.

\subsubsection{Pile Spacing}

The pile spacing, $S$, which is the center-to-center distance between adjacent piles, is one of the most important parameters affecting the thermal performance of an energy pile group with a deeply penetrating U-shaped heat exchanger. In practical projects, pile spacing falls within a range, usually four to six times the pile diameter (data from Chinese code for design of building foundation, GB50007-2011). However, in this study, the range of pile spacing is enlarged (as presented in Table 8) to obtain more general conclusions. The outlet water temperature after $720 \mathrm{~h}$ of operation as a function of pile spacing for three piles in the group is presented in Figure 11 and Table 9. As indicated, an increase in the pile spacing leads to a decrease in the outlet water temperature for all three piles, which implies that more heat is transferred into the soil. When the pile spacing is $2.1 \mathrm{~m}$ (i.e., 3.5 times the pile diameter), the outlet water temperature difference of the three piles is at its maximum of $0.54{ }^{\circ} \mathrm{C}$. The corner pile indicates a heat transfer rate that is $18.3 \%$ higher than that of the central pile. As the pile spacing increases, the outlet water temperature difference of the three piles also decreases. When the pile spacing is $4.1 \mathrm{~m}$ (i.e., 6.8 times the pile diameter), the difference of the three piles approaches 0 . The outlet water temperatures of the three piles are $31.00^{\circ} \mathrm{C}, 31.02{ }^{\circ} \mathrm{C}$, and $30.96^{\circ} \mathrm{C}$, which are close to the results of the single pile, $31.03^{\circ} \mathrm{C}$, presented in Figure 11 and Table 9 . When the pile spacing is larger than $4.1 \mathrm{~m}$, the outlet water temperatures of the three piles stabilize and match that of a single pile. Purely from the standpoint of thermal performance, the pile spacing is recommended to be more 
than 6.8 times the pile diameter to reduce the influence of the pile group on the heat transfer capacity. However, in practice, we need to combine the mechanical analysis and site limitations to determine a rational pile spacing. For example, a nonenergy pile can be set up at the middle of two adjacent energy piles to double the pile spacing between energy piles and increase the heat transfer capacity of every energy pile, and only half of the energy pile is needed.

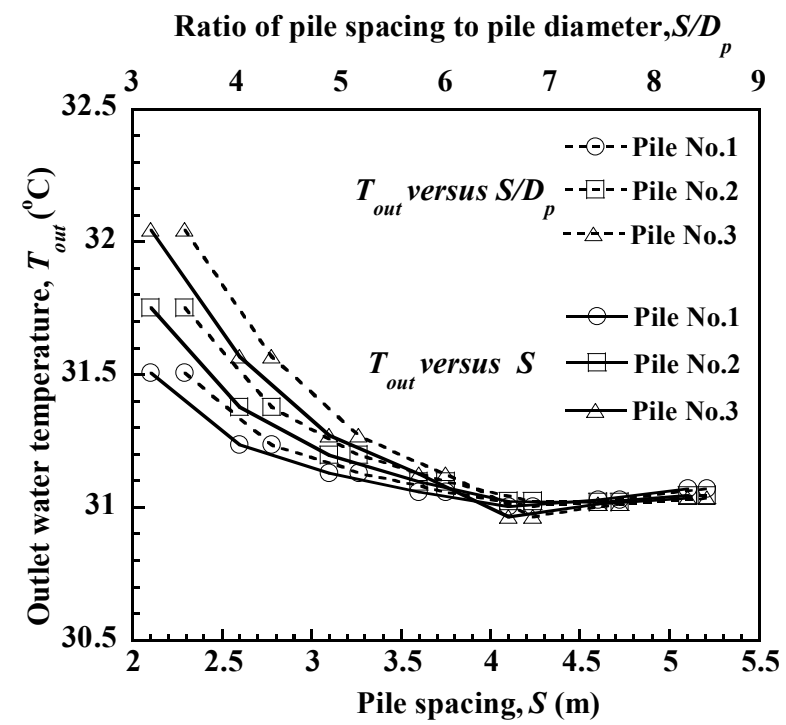

Figure 11. Outlet water temperature variation for different pile spacings, $S$, for the energy pile group with a deeply penetrating 1-U-shaped heat exchanger after $720 \mathrm{~h}$.

Table 9. Simulation results for different pile spacings, $S$ (keeping all other values consistent with the reference values in Table 8).

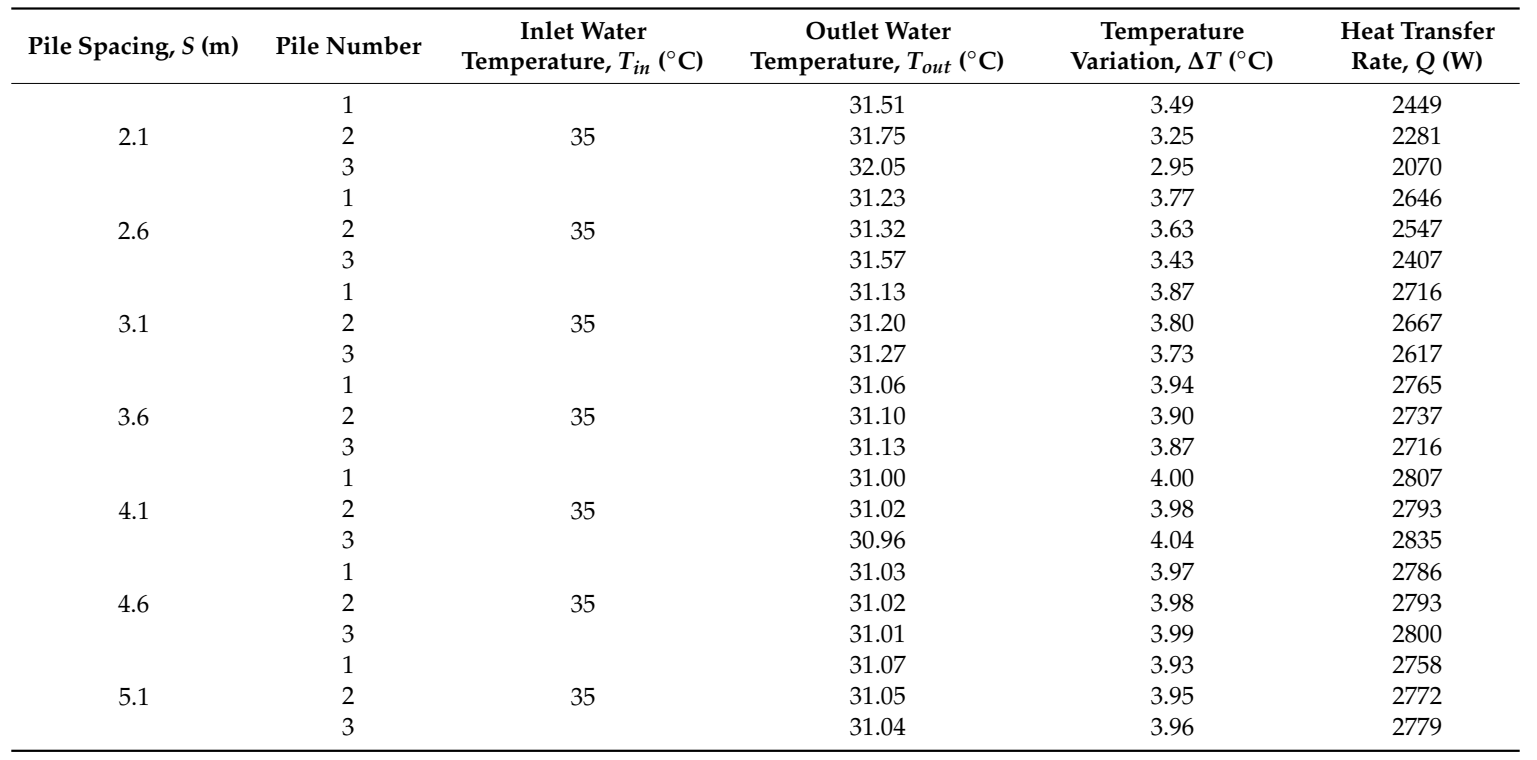

\subsubsection{Pile Diameter}

The pile diameter is another important design parameter influencing the thermal performance of the energy pile group with a deeply penetrating U-shaped heat exchanger. Four different values, presented in Table 8, varying from $400 \mathrm{~mm}$ to $1000 \mathrm{~mm}$, are analyzed. In practical projects, most piles are in the central position, so Pile \#3 is taken as a typical example unless otherwise stated. The simulation results are presented in Figure 12 and Table 10. As indicated, the pile diameter has a significant influence on the heat transfer capacity of Pile \#3, and a larger pile diameter yields a lower outlet water 
temperature and greater heat transfer capacity. When the pile diameter increases from $400 \mathrm{~mm}$ to $1000 \mathrm{~mm}$, the outlet water temperature decreases from $31.81^{\circ} \mathrm{C}$ to $31.32{ }^{\circ} \mathrm{C}$ (i.e., $0.49^{\circ} \mathrm{C}$ reduction), and the corresponding heat transfer rate increases from $2238 \mathrm{~W}$ to $2582 \mathrm{~W}$ ( $15.4 \%$ increase). The reason for this is that piles with larger cross-sections equivalently replace soil with concrete, which has better heat-conducting properties.

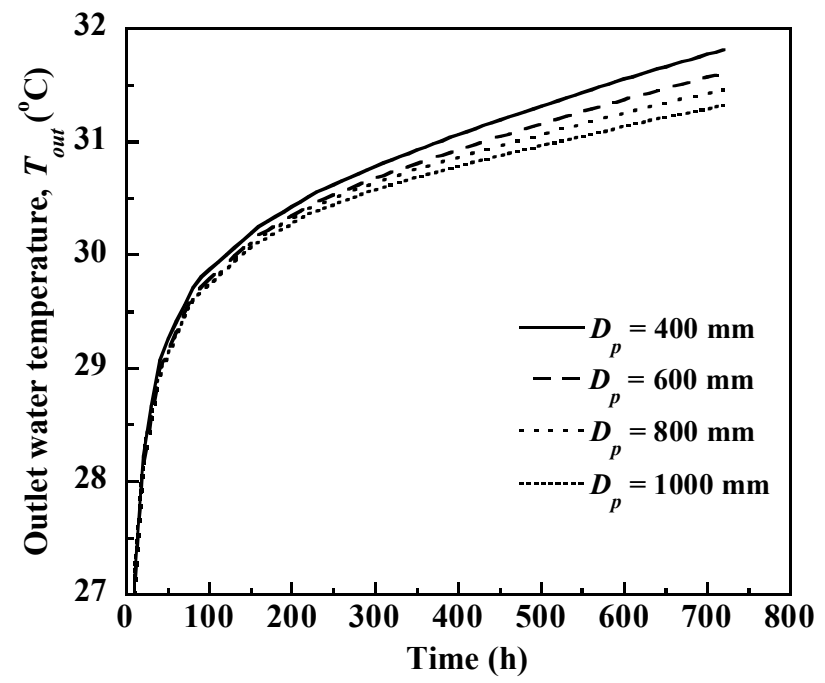

Figure 12. Outlet water temperature variation for different pile diameters, $D_{p}$.

Table 10. Simulation results for different pile diameters, $D_{p}$ (keeping all other values consistent with the reference values in Table 8).

\begin{tabular}{ccccc}
\hline Pile Diameter, $\boldsymbol{D}_{\boldsymbol{p}}(\mathbf{m m})$ & $\begin{array}{c}\text { Inlet Water } \\
\text { Temperature, } \boldsymbol{T}_{\boldsymbol{i n}}\left({ }^{\circ} \mathbf{C}\right)\end{array}$ & $\begin{array}{c}\text { Outlet Water } \\
\text { temperature, } \boldsymbol{T}_{\text {out }}\left({ }^{\circ} \mathbf{C}\right)\end{array}$ & $\begin{array}{c}\text { Temperature } \\
\text { Variation, } \boldsymbol{\Delta} \boldsymbol{T}\left({ }^{\circ} \mathbf{C}\right)\end{array}$ & $\begin{array}{c}\text { Heat Transfer } \\
\text { Rate, } \boldsymbol{Q}(\mathbf{W})\end{array}$ \\
\hline 400 & \multirow{3}{*}{35} & 31.81 & 3.19 & 2238 \\
600 & & 31.61 & 3.39 & 2379 \\
800 & & 31.46 & 3.54 & 2484 \\
1000 & & 31.32 & 3.68 & 2582 \\
\hline
\end{tabular}

\section{Conclusions}

First, this study adopted a numerical model of a pile group, which was verified against the experimental results in the literature. Second, the deeply penetrating U-shaped configuration was compared with traditional U-shaped and W-shaped configurations to prove its superiority. Third, a deeply penetrating $U$-shaped pile group was analyzed to research the effects of pile groups on heat transfer. Three typical pile positions in two arrangements were compared with a single pile. Last, a parametric analysis, including the pile spacing, pile diameter, types, and thermal parameters of the soil, was conducted to investigate the parameters affecting the thermal performance of the energy pile group with a deeply penetrating U-shaped heat exchanger.

The main findings of this study are as follows:

(1) Compared with the traditional U-shaped configuration, the proposed deeply penetrating U-shaped configuration indicated superior thermal performance, with a $122 \%$ increase in the total heat transfer rate, $Q$, and a $9 \%$ increase in the heat transfer rate per unit length of the tube, $Q^{*}$. Compared with the traditional $\mathrm{W}$-shaped configuration, the proposed configuration indicated a $54 \%$ increase in $Q$ and a $50 \%$ increase in $Q^{*}$.

(2) For the pile group, $300 \mathrm{~h}$ is not long enough to cause thermal interference. After $300 \mathrm{~h}$, thermal interference becomes evident, which causes a decrease in the heat transfer capacity. The corner pile indicates a nonnegligible heat transfer rate $6.8 \%$ and $9.9 \%$ higher than the central pile in quincuncial and squared arrangements, respectively, according to the example in this study. 
(3) An increase in the pile spacing leads to an increase in the heat transfer rate. Purely from the standpoint of thermal performance, the pile spacing is recommended to be more than 6.8 times the pile diameter to reduce the influence of the pile group on the heat transfer capacity.

(4) The heat transfer rate increases as the pile diameter increases. An increase of approximately $15.4 \%$ can be observed if the pile diameter increases from $400 \mathrm{~mm}$ to $1000 \mathrm{~mm}$.

Energy piles are inspiring in terms of saving energy and circulating heat. Deeply penetrating U-shaped energy pile groups were analyzed for cooling mode to increase their heat transfer capacity in this study. It would be necessary to carry out a study on deeply penetrating U-shaped energy pile groups for the case of extreme heating and cooling cycles in the future. More numerical and experimental studies for heating mode or combining cooling and heating are required to better understand and make full use of this type of heat exchange system.

Author Contributions: Conceptualization, H.P. and J.C.; methodology, W.L. and J.C.; software, W.L.; formal analysis, H.P. and W.L.; writing—original draft preparation, W.L.; writing-review and editing, H.P. and J.C.; supervision, H.P. and J.C. All authors have read and agreed to the published version of the manuscript.

Funding: This research was funded by the Major Technological Innovation Program of Hubei Province, China (Grant No. 2017AAA128 and No. 2018AAA028).

Conflicts of Interest: The authors declare no conflict of interest.

\section{References}

1. Tarnawski, V.R.; Leong, W.H.; Momose, T.; Hamada, Y. Analysis of ground source heat pumps with horizontal ground heat exchangers for northern Japan. Renew. Energy 2009, 34, 127-134. [CrossRef]

2. Self, S.J.; Reddy, B.V.; Rosen, M.A. Geothermal heat pump systems: Status review and comparison with other heating options. Appl. Energy 2013, 101, 341-348. [CrossRef]

3. Hamada, Y.; Saitoh, H.; Nakamura, M.; Kubota, H.; Ochifuji, K. Field performance of an energy pile system for space heating. Energy Build. 2007, 39, 517-524. [CrossRef]

4. Benli, H.; Durmuş, A. Evaluation of ground-source heat pump combined latent heat storage system performance in greenhouse heating. Energy Build. 2009, 41, 220-228. [CrossRef]

5. Ozturk, M. Energy and exergy analysis of a combined ground source heat pump system. Appl. Therm. Eng. 2014, 73, 362-370. [CrossRef]

6. Li, Z. A new constant heat flux model for vertical U-tube ground heat exchangers. Energy Build. 2012, 45, 311-316. [CrossRef]

7. Gu, Y.; O'Neal, D.L. Development of an equivalent diameter expression for vertical U-Tubes used in ground-coupled heat pumps. ASHRAE Trans. 1998, 104, 347-355.

8. Beier, R.A. Transient heat transfer in a U-tube borehole heat exchanger. Appl. Therm. Eng. 2014, 62, 256-266. [CrossRef]

9. Yang, W.; Shi, M.; Liu, G.; Chen, Z. A two-region simulation model of vertical U-tube ground heat exchanger and its experimental verification. Appl. Energy 2009, 86, 2005-2012. [CrossRef]

10. Adam, D.; Markiewicz, R. Energy from earth-coupled structures, foundations, tunnels and sewers. Geotechnique 2009, 59, 229-236. [CrossRef]

11. Brandl, H. Energy foundations and other thermo-active ground structures. Geotechnique 2006, 56, 81-122. [CrossRef]

12. Morino, K.; Oka, T. Study on heat exchanged in soil by circulating water in a steel pile. Energy Build. 1994, 21, 65-78. [CrossRef]

13. Park, H.; Lee, S.R.; Yoon, S.; Choi, J.C. Evaluation of thermal response and performance of PHC energy pile: Field experiments and numerical simulation. Appl. Energy 2013, 103, 12-24. [CrossRef]

14. Abdelaziz, S.L.; Olgun, C.G.; Martin, J.R., II. Design and operational considerations of geothermal energy piles. In Proceedings of the Geo-Front. 2011 Adv. Geotech. Eng., Dallas, TX, USA, 13-16 March 2011; pp. 450-459.

15. Abdelaziz, S.L.; Ozudogru, T.Y. Selection of the design temperature change for energy piles. Appl. Therm. Eng. 2016, 107, 1036-1045. [CrossRef] 
16. Caulk, R.; Ghazanfari, E.; McCartney, J.S. Parameterization of a calibrated geothermal energy pile model. Geomech. Energy Environ. 2016, 5, 1-15. [CrossRef]

17. You, S.; Cheng, X.; Yu, C.; Dang, Z. Effects of groundwater flow on the heat transfer performance of energy piles: Experimental and numerical analysis. Energy Build. 2017, 155, 249-259. [CrossRef]

18. Batini, N.; Rotta Loria, A.F.; Conti, P.; Testi, D.; Grassi, W.; Laloui, L. Energy and geotechnical behaviour of energy piles for different design solutions. Appl. Therm. Eng. 2015, 86, 199-213. [CrossRef]

19. Jalaluddin; Miyara, A.; Tsubaki, K.; Inoue, S.; Yoshida, K. Experimental study of several types of ground heat exchanger using a steel pile foundation. Renew. Energy 2011, 36, 764-771. [CrossRef]

20. Bezyan, B.; Porkhial, S.; Mehrizi, A.A. 3-D simulation of heat transfer rate in geothermal pile-foundation heat exchangers with spiral pipe configuration. Appl. Therm. Eng. 2015, 87, 655-668. [CrossRef]

21. Zhao, Q.; Liu, F.; Liu, C.; Tian, M.; Chen, B. Influence of spiral pitch on the thermal behaviors of energy piles with spiral-tube heat exchanger. Appl. Therm. Eng. 2017, 125, 1280-1290. [CrossRef]

22. Carotenuto, A.; Marotta, P.; Massarotti, N.; Mauro, A.; Normino, G. Energy piles for ground source heat pump applications: Comparison of heat transfer performance for different design and operating parameters. Appl. Therm. Eng. 2017, 124, 1492-1504. [CrossRef]

23. Park, S.; Sung, C.; Jung, K.; Sohn, B.; Chauchois, A.; Choi, H. Constructability and heat exchange efficiency of large diameter cast-in-place energy piles with various configurations of heat exchange pipe. Appl. Therm. Eng. 2015, 90, 1061-1071. [CrossRef]

24. Huang, G.; Yang, X.; Liu, Y.; Zhuang, C.; Zhang, H.; Lu, J. A novel truncated cone helix energy pile: Modelling and investigations of thermal performance. Energy Build. 2018, 158, 1241-1256. [CrossRef]

25. Bouhacina, B.; Saim, R.; Oztop, H.F. Numerical investigation of a novel tube design for the geothermal borehole heat exchanger. Appl. Therm. Eng. 2015, 79, 153-162. [CrossRef]

26. Jahanbin, A. Thermal performance of the vertical ground heat exchanger with a novel elliptical single U-tube. Geothermics 2020, 86, 101804. [CrossRef]

27. Pu, H.; Lyu, W.; Xiao, H.; Hu, D.; Ruan, Q. A kind of high-efficiency heat-exchanger energy pile. China Patent No. 201820283459.0, 2 October 2018. (In Chinese).

28. Xiao, H.; Gao, H.Z.C.; Xiao, Y.; Ma, Q.; Que, M.; Dong, Y.; Liu, Y.; Li, L. Construction method for deep-buried heat exchange system of cast-in-place energy pile. China Patent No. 201810100503.4, 15 November 2019. (In Chinese).

29. You, S.; Cheng, X.; Guo, H.; Yao, Z. In-situ experimental study of heat exchange capacity of CFG pile geothermal exchangers. Energy Build. 2014, 79, 23-31. [CrossRef]

30. Carslaw, H.S.; Jaeger, J.C. Conduction of Heat in Solids, 2nd ed.; Clarendon Press: Oxford, UK, 2008.

31. Taler, D. Numerical Modelling and Experimental Testing of Heat Exchangers; Springer: Cham, Switzerland, 2019; pp. 38-46.

32. Gao, J.; Zhang, X.; Liu, J.; Li, K.S.; Yang, J. Thermal performance and ground temperature of vertical pile-foundation heat exchangers: A case study. Appl. Therm. Eng. 2008, 28, 2295-2304. [CrossRef]

33. Suryatriyastuti, M.E.; Mroueh, H.; Burlon, S. Understanding the temperature-induced mechanical behaviour of energy pile foundations. Renew. Sustain. Energy Rev. 2012, 16, 3344-3354. [CrossRef]

Publisher's Note: MDPI stays neutral with regard to jurisdictional claims in published maps and institutional affiliations.

(C) 2020 by the authors. Licensee MDPI, Basel, Switzerland. This article is an open access article distributed under the terms and conditions of the Creative Commons Attribution (CC BY) license (http://creativecommons.org/licenses/by/4.0/). 